EDITORIAL

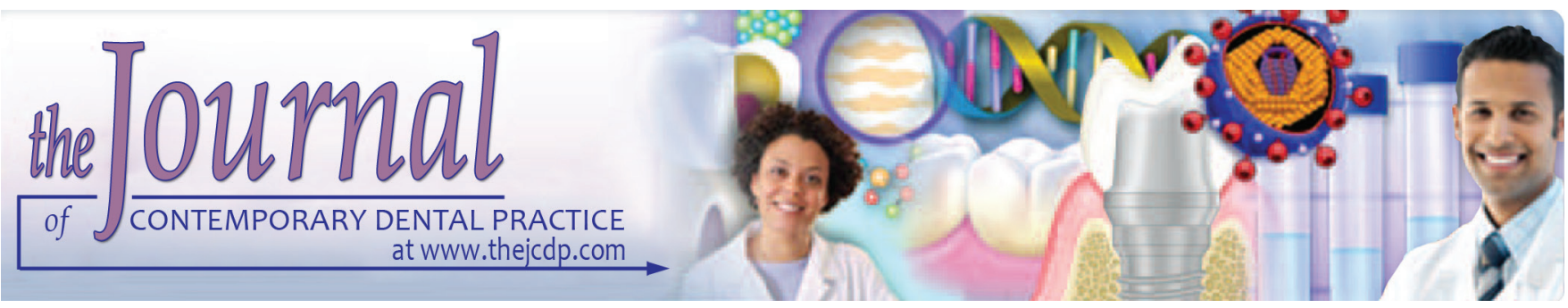

\title{
Gold Nanoparticles: A Novel Approach in Early Detection of Oral Cancers
}

\author{
${ }^{1}$ Gargi S Sarode, ${ }^{2}$ Nikunj Maniyar, ${ }^{3}$ Nilookumari Choudhary, ${ }^{4}$ Sachin C Sarode, ${ }^{5}$ Shankargouda Patil
}

How to cite this article: Sarode GS, Maniyar N, Choudhary N, Sarode SC, Patil S. Gold Nanoparticles: A Novel Approach in Early Detection of Oral Cancers. J Contemp Dent Pract 2018;19(4):357-358.

\section{Source of support: Nil}

\section{Conflict of interest: None}

Oral squamous cell carcinoma (OSCC) holds a place among the 10 most common cancers in the world with a reported increase in its incidence every year, particularly in western and Asian countries. ${ }^{1}$ Of the reported cases, majority of oral cancers are preceded by precancerous lesions. ${ }^{2}$ Expeditious and untimely detection of oral cancer is paramount for improving the survival rate of this disease as any delay in its diagnosis is accompanied with poor prognosis despite advanced treatment approaches.

Even though oral biopsy and histopathological examination of the lesion stand as the gold standard, it is time consuming, invasive, and most importantly can be performed only when the lesion is spotted within the oral cavity. Early clinical changes and lesions that may be present in hidden areas, such as floor of the mouth or base of the tongue may go undetected. ${ }^{3}$ Moreover, few controversies exist regarding the subjectivity in reporting the dysplastic changes. ${ }^{4}$ Of the recent less invasive early diagnostic techniques for oral cancer, high-resolution imaging of oral tissues with novel optical systems and the

\footnotetext{
${ }^{1-4}$ Department of Oral Pathology and Microbiology, Dr. D.Y. Patil Dental College \& Hospital, Dr. D.Y. Patil Vidyapeeth, Pune Maharashtra, India

${ }^{5}$ Department of Preventive Dental Sciences, College of Dentistry Jazan University, Jazan, Kingdom of Saudi Arabia

Corresponding Author: Gargi S Sarode, Department of Oral Pathology and Microbiology, Dr. D.Y. Patil Dental College \& Hospital, Dr. D.Y. Patil Vidyapeeth, Pune, Maharashtra, India Phone: +919823871462, e-mail: gargi14@gmail.com
}

chemical analysis of saliva serve as some of the valuable tools. Nevertheless, these techniques have certain limitations, most importantly their low specificity. ${ }^{3}$

To overcome the limitations of the available imaging and chemical-based diagnostic methods for cancer detection, gold nanoparticles (GNPs) have recently been explored for early diagnosis of oral cancer. Gold nanoparticles hold favorable physiochemical properties providing an optical contrast to differentiate malignant from normal cells. ${ }^{5}$ Depending upon their size, shape, and physical properties, they can be nanospheres, nanorods, nanoshells, and nanocages. They are capable of improving and scattering reflection of light irradiated in their surface plasmon resonance frequency, discriminating oral cancer cells from that of normal cells. ${ }^{6}$ Head and neck squamous cell carcinoma has been reported to show a relatively higher expression of epidermal growth factor receptor (EGFR) with a stepwise increment in the EGFR with increase in the degree of dysplasia ${ }^{7}$ and ultimately higher oral cancer risk. ${ }^{8}$ Gold nanoparticles can be conjugated with anti-EGFR antibodies so as to map the expression of the biomarker for molecular imaging and early diagnosis of oral cancer. For bioconjugation, to prevent aggregation, a shielding coating of polyethylene glycol is absorbed on Gold Nanorods. One of the in vitro studies reports conjugation of GNPs with UM-A9 antibodies that home specifically to squamous cell carcinoma of head and neck facilitating early oral cancer detection. ${ }^{6}$ Cell imaging using dark field light surface plasmon resonance scattering and photoacoustic tomography also reports use of GNPs. ${ }^{9}$ In addition, use of near-infrared absorbing GNPs greatly improves image contrast. Raman spectroscopy serves as the most propitious imaging technique for GNP-based contrast agents. Studies have shown that when conjugated with appropriate antibody, GNPs enhance and sharpen the Raman spectrum. This can be attributed to high-surface plasmon field of the nanoparticles. ${ }^{10}$ Fixler et $\mathrm{al}^{11}$ demonstrated the power 
of direct diffusion reflection scanning for identifying the cancerous process in a tissue specimen of rat models of OSCC that utilizes the unique absorption properties of GNPs. They significantly alter the optical properties of invasive cancer as well as carcinoma-in-situ, thus allowing their discrimination from normal tissue. However, this simple and promising approach demands further clinical study.

Apart from its use as a diagnostic aid, GNPs also hold a place in cancer therapeutics that includes targeting the cancer cells by photothermal ablation. ${ }^{12}$ The property of GNPs to inhibit the proangiogenic growth factors facilitates termination of tumor cell proliferation and survival. $^{13}$

Our increasing knowledge of cancer-associated biomolecular changes occurring prior to the clinically evident cancerous lesion combined with nanotechnology opens door for early and advanced cancer detection and treatment. Oral cancer detection through GNPs is a simple, nontoxic, and less invasive technique proving to be a novel diagnostic method in the field of cancer. Such molecular techniques have the ability to detect oral cancer at its earliest even prior to the establishment of lesion clinically. However, few aspects of GNPs like tumor target efficacy, their ability to escape reticuloendothelial system and toxicity are some voids that require further attention of the researchers.

\section{REFERENCES}

1. Lee CC, Ho HC, Su YC, Chen PC, Yu CH, Yang CC. Comparison of different comorbidity measures for oral cancer patients with surgical intervention: a longitudinal study from a single cancer center. Auris Nasus Larynx 2016 Jun;43(3):322-329.

2. Sarode SC, Sarode GS, Tupkari JV. Oral potentially malignant disorders: a proposal for terminology and definition with review of literature. J Oral Maxillofac Pathol 2014 Sep;18(Suppl 1): S77-S80.

3. Kah JC, Kho KW, Lee CG, James C, Sheppard R, Shen ZX, Soo KC, Olivo MC. Early diagnosis of oral cancer based on the surface plasmon resonance of gold nanoparticles. Int J Nanomedicine 2007 Dec;2(4):785-798.

4. Lee JJ, Hung HC, Cheng SJ, Chiang CP, Liu BY, Yu CH, Jeng JH, Chang $\mathrm{HH}$, Kok SH. Factors associated with underdiagnosis from incisional biopsy of oral leukoplakic lesions. Oral Surg Oral Med Oral Pathol Oral Radiol Endod 2007 Aug;104(2):217-225.

5. Ravindran R. Nanotechnology in cancer diagnosis and treatment: an overview. J Oral Maxillofac Pathol 2011 Jan-Jun;2(1): 101-106.

6. Fotedar V, Fotedar S, Bharadwaj V. Role of gold nanoparticles in the early detection of oral cancers. Indian J Stomatol 2014;5(1):7-11.

7. Shin DM, Ro JY, Hong WK, Hittelman WN. Dysregulation of epidermal growth factor receptor expression in premalignant lesions during head and neck tumorigenesis. Cancer Res 1994 Jun;54(12):3153-3159.

8. Taoudi Benchekroun M, Saintigny P, Thomas SM, El-Naggar AK, Papadimitrakopoulou V, Ren H, Lang W, Fan YH, Huang J, Feng L, et al. Epidermal growth factor receptor expression and gene copy number in the risk of oral cancer. Cancer Prev Res (Phila) 2010 Jul;3(7):800-809.

9. Li ZB, Cai W, Chen X. Semiconductor quantum dots for in vivo imaging. J Nanosci Nanotechnol 2007 Aug;7(8):2567-2581.

10. Tan Y, Yan B, Xue L, Li Y, Luo X, Ji P. Surface-enhanced Raman spectroscopy of blood serum based on gold nanoparticles for the diagnosis of the oral squamous cell carcinoma. Lipids Health Dis 2017 Apr;16:73.

11. Fixler D, Ankri R, Kaplan I, Novikov I, Hirshberg A. Diffusion reflection: a novel method for detection of oral cancer. J Dent Res 2014 Jun;93(6):602-606.

12. Lal S, Grady NK, Goodrich GP, Halas NJ. Profiling the near field of a plasmonic nanoparticle with Raman-based molecular rulers. Nano Lett 2006 Oct;6(10):2338-2343.

13. Lal S, Clare SE, Halas NJ. Nanoshell-enabled photothermal cancer therapy: impending clinical impact. Acc Chem Res 2008 Dec;41(12):1842-1851. 